\title{
New material and reinterpretation of the Late Cretaceous eutherian mammal Paranyctoides from Uzbekistan
}

\author{
Alexander O. Averianov and J. David Archibald \\ Acta Palaeontologica Polonica 58 (1), 2013: 17-23 doi: http://dx.doi.org/10.4202/app.2011.0131
}

Paranyctoides aralensis, based on a partially known set of lower postcanines from the Turonian Bissekty Formation of

Uzbekistan, is proposed to be a junior subjective synonym of Sailestes quadrans, itself

based on an M1 from the same stratigraphic unit. As a result, the latter taxon is recombined as Paranyctoides quadrans comb. nov. Based on newly collected or recognized specimens, we show that this species has four lower incisors, including a procumbent i1 and a relatively small i4, as well as five double-rooted premolars, the smallest of which (p3) can be lost ontogenetically. The p5 of this species is premolariform, rather than molariform as previously thought based on an erroneous identification, and resembles North American species of Paranyctoides in the presence of a small, cingulid-like paraconid and a distal talonid cusp, as well as the absence of a metaconid. The lower molars of Paranyctoides are unique among Late Cretaceous eutherians in having a larger, lingually placed paraconid. Paranycoides probably is the sister taxon of the Late Cretaceous Zhelestidae.

Key words: Mammalia, Eutheria, Paranyctoides, Late Cretaceous, Uzbekistan.

Alexander Averianov [dzharakuduk@mail.ru], Zoological Institute, Russian Academy of Sciences, Universitetskaya nab. 1, 199034, Saint Petersburg, Russia; J. David Archibald [darchibald@ sunstroke.sdsu.edu], Department of Biology, San Diego State University, San Diego, California, 92182-4614, USA.

This is an open-access article distributed under the terms of the Creative Commons Attribution License (for details please see creativecommons.org), which permits unrestricted use, distribution, and reproduction in any medium, provided the original author and source are credited. 
For 5 Full text (250.1 kB) 